\title{
Convergent Synthesis of PAMAM-like Dendrimers from Azide-functionalized PAMAM Dendrons
}

\author{
Jae Wook Lee, "Jung Hwan Kim, Byung-Ku Kim, Ji Hyeon Kim, ${ }^{\dagger}$ Won Suk Shin, ${ }^{\ddagger}$ Sung-Ho Jin, ${ }^{\ddagger}$ and Myunghak Kim ${ }^{\sharp}$ \\ Department of Chemistry, Dong-A University, Busan 604-714, Korea. "E-mail, jlee@donga.ackr \\ "Department of Chemical \& Biochemical Engineering, Donggik University, Seoul 100-715, Korea \\ ¿Department of Chemistry Education \& Center for Plastic Information System, Pusan National University, Busan 609-735, Korea

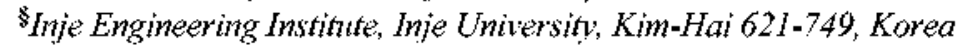 \\ Received Angust 11, 2006
}

\begin{abstract}
The convergent synthesis of symmetric P $\mathrm{MM} M \mathrm{M}$-like dendrimers from azide-functionalized poly(amidoamine) (PAM $\mathrm{MM}$ ) dendrons and two different multi-alkynes was investigated. The stitching method was based on the click chemistry protocol, i.e., the copper-catalyzed cycloaddition reaction between an alkyne and an azide.
\end{abstract}

Key Words : Alkyne, Azide, Click chemistry, PAMAM dendrimers, 1,2,3-Triazoles

\section{Introduction}

Dendrimers represent a novel type of polymeric material that has generated much interest in diverse areas due to their unique structure and properties, and have served as functional objects in nanotechnology and nanoscience.' Their unique structural features include highly branched and welldefined structure, globular shape, and controlled surface functionalities. Dendrimers are prepared by repetition of a given set of reactions using either divergent or convergent strategies. The two most widely studied dendrimer families are the Fréchet-type polyether and the Tomalia-type PAMAM dendrimers. The convergent approach to dendrimer synthesis introduced by Fréchet and co-workers revolutionized the synthetic approaches to monodisperse dendrimers. ${ }^{2}$ The convergent methodology installs the core in the final step, enabling the incorporation of functionalities. It provides greater structural control than the divergent approach due to its relatively low number of coupling reactions at each growth step. The ability to prepare well-defined (un)symmetrical dendrimers is the most attractive features of the convergent synthesis. On the other hand, PAMAM dendrimers are synthesized by the divergent approach. ${ }^{3}$

PAMAM dendrimers, which are nanoscopic spherical macromolecules composed of polyamidoamino units with repeating dendritic branching, have been extensively studied in many fields such as drug, drug and gene delivery, and self-assembly. ${ }^{+}$The early synthetic efforts in PAMAM dendrimer synthesis applied the divergent synthesis procedure building the dendrimers from the core by an iterative synthetic procedure. ${ }^{3}$ Recent research emphas is seems to shift from the synthesis of novel dendrimers to their properties and potential applications, but future applications of PAMAM dendrimers rely on efficient and practical synthetic procedures. The convergent approach allows for a large degree of chemical diversity such that functional groups can be incorporated at nearly central position in the dendritic architecture. The synthesis of PAMAM dendrimers via the convergent approach has presented a significant challenge.
But, an example in the convergent synthesis of PAMAM dendrimers by the amide coupling between carboxylic acid and amine is reported. ${ }^{5}$

The reactions employed in the synthesis of dendrimers should be high yielding without any side reactions. Well known processes, such as the Michael reaction, Williamson ether synthesis, amidations and reductions have been used extensively in the synthesis of dendrimers. ${ }^{6}$ Recently the click chemistry ${ }^{7.8}$ which is the Cu(I)-catalyzed Huisgen [2+ 3] dipolar cycloaddition reaction between an organic azide and a terminal alkyne, has found many applications ${ }^{9}$ in combinatorial and organic chemistry, bioconjugations, and materials science. The reaction is characterized by very high yields, mild and simple reaction conditions, oxygen and water tolerance, and ease of product isolation. It is highly chemoselective affording only the desired 1,2,3-triazole even in the presence of a large variety of other functional groups. The route is clearly a breakthrough in the synthesis of dendrimers and dendritic and polymer materials. Although there are many reports to synthesize the triazole-mediated dendritic materials using click chemistry, ${ }^{10}$ relatively few applications in PAMAM dendrimer synthesis have been reported. ${ }^{11}$ Because of the high yields and lack of byproducts provided by the click chemistry for stitching together dendrons and core unit, the various dendrimers having functional building block at core could be obtained easily and shown the characteristic behaviors. Due to our interest in developing new functinonal dendrimers, we became involved in exploring efficient cycloaddition reactions that provide an easy access to dendrimers. Herein we present the convergent synthesis of poly(amidoamine) (PAMAM) dendrimers using click chemistry between azide-functionalized poly(amidoamine) (PAMAM) dendrons 1-Dm and two multi-alkynes cores.

\section{Results and Discussion}

The synthetic strategy for PAMAM dendrimers, linked by the triazole units, utilized a convergent method using the 


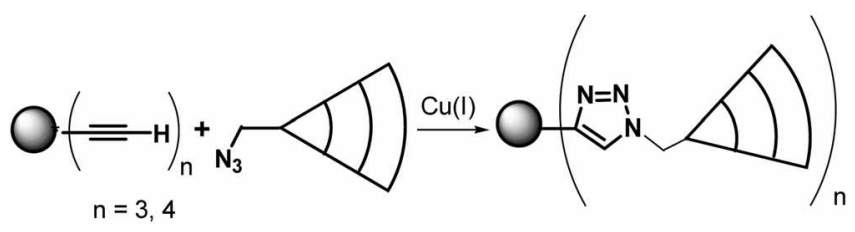

Figure 1. Synthetic strategies of dendrimers.

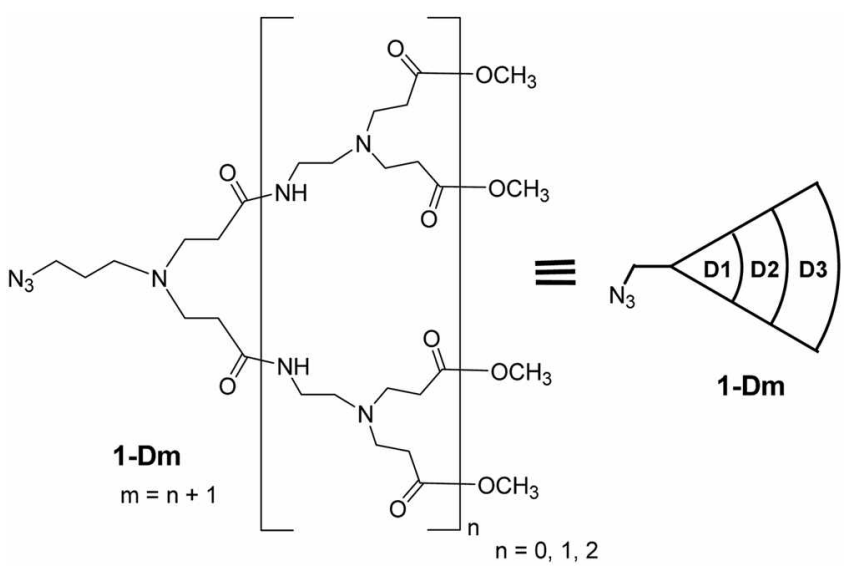

Figure 2. Structures of azide-functionalized PAMAM dendrons 1Dm.

azide-functionalized PAMAM dendrons 1-Dm and the multi(alkynes) cores (Figure 1). The azide-functionalized PAMAM dendrons 1-Dm ( $\mathrm{m}=1-3$; generation of dendron) shown in Figure 2 are synthesized by the divergent approach using azidopropylamine as an azido-focal point. "lt This methodology involves typical stepwise and iterative twostep reaction sequences, consisting of amidation of methy] ester groups with a large excess of ethylenediamine and Michael addition of primary amines with methyl acrylate to produce methyl ester teminal groups.

The inward growth employed by the convergent synthesis is ideally suited for the attachment of diverse core moieties. As a result, building dendrimers via the convergent approach allows for the synthesis of symmetric dendrimers and for specific incorporation of functions into the dendrimer interior. To efficiently connect the azide focal point PAMAM dendrons with core unit(s) via the convergent approach, we intended to use the click condition using $\mathrm{Cu}$ (I) species. 1,3,5-Tris-prop-2-ynyloxybenzene 2 and 4,4'-(3,5-bis(propargyloxy)benzyloxy)bisphenyl 3 were designed to serve as the alkyne functionalities for dendrimer growth via click reactions with the dendrons. These compounds were synthesized readily from the tri-propargylation of 1,3,5-tri-hydroxybenzene with propargyl bromide and the bis-alkylations of 4,4-bisphenol with 3,5-bis(propargyloxy)benzyl chloride in the presence of a base, respectively (Scheme 1). The structures of these compounds were confirmed by ${ }^{1} \mathrm{H}$ and ${ }^{13} \mathrm{C}$ NMR spectroscopy, IR spectroscopy, and mass spectra. The IR spectra show the terminal $\equiv \mathrm{C}-\mathrm{H}$ at $3290 \mathrm{~cm}^{-1}$ and $\mathrm{C} \equiv \mathrm{C}$ triple bond at $2122 \mathrm{~cm}^{-1}$ for compound 2 and the teminal $\equiv \mathrm{C}-\mathrm{H}$ at $3290 \mathrm{~cm}^{-1}$ and $\mathrm{C} \equiv \mathrm{C}$ triple bond at $212 \mathrm{I}$ $\mathrm{cm}^{-1}$ for compound 3 .
To test the effectiveness of the dipolar cycloaddition reactions of the tri(alkynes) core 2 and azide-dendrons 1Dm (Scheme 2), we have screened with several conditions using various $\mathrm{Cu}(\mathrm{I})$ sources in different solvents. ${ }^{8.9}$ We have found that the reaction conducted from the condition of 5 mol $\%$ of $\mathrm{CuSO}_{4}, 5 \mathrm{H}_{2} \mathrm{O}$ with $10 \mathrm{~mol} \%$ of sodium ascorbate with respect to the alkyne in a $4: 1$ solvent ratio of THF to $\mathrm{H}, \mathrm{O}$ for $7.5 \mathrm{~h}$ at room temperature afforded the desired
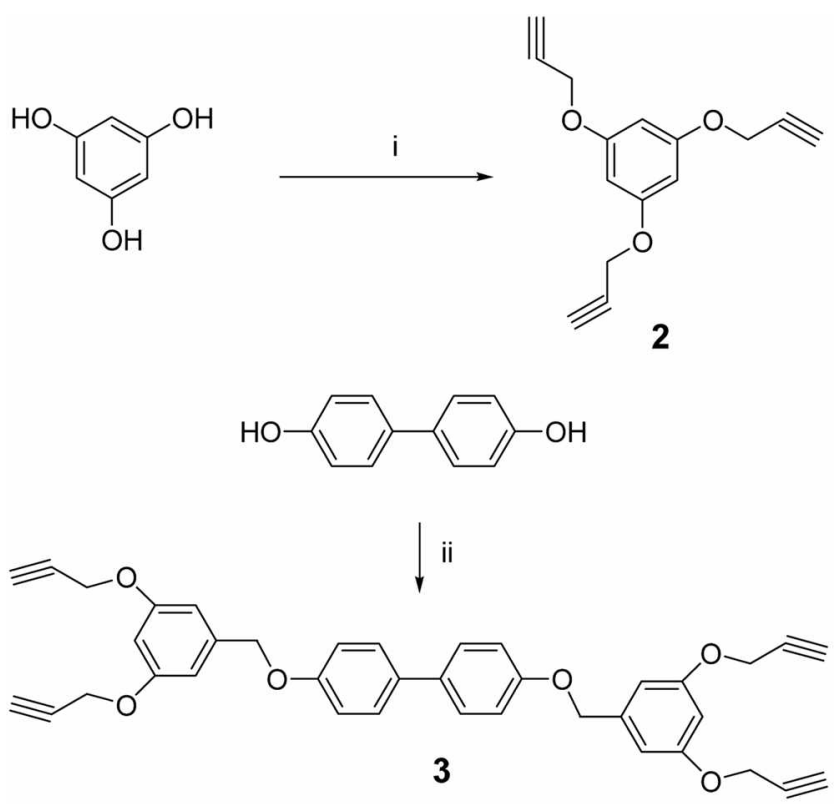

Scheme 1. Reagents and conditions: (1) Propargyl bromide, $\mathrm{K}_{2} \mathrm{CO}_{3}, 18-\mathrm{crown}-6, \mathrm{CH}_{3} \mathrm{CN}$, reflux, $16 \mathrm{~h}$; (ii) 3,5-bis(propargyloxy)benzyl chloride, $\mathrm{K}_{2} \mathrm{CO}_{3}$, DMF, $60^{\circ} \mathrm{C}, 24 \mathrm{~h}$.

product 4-G1 in yield of 90\%. The generation and disappearance of the mono and di-triazole derivatives were monitored by TLC runs of the reaction mixture. Given the success in the synthesis of first generation dendrimer, we expanded this reaction to get higher generation dendrimers with $5 \mathrm{~mol} \%$ of $\mathrm{CuSO}_{4} \cdot 5 \mathrm{H}_{2} \mathrm{O}$ with $10 \mathrm{~mol} \%$ of sodjum ascorbate with respect to the alkyne in a 4:1 solvent ratio of THF to $\mathrm{H}_{2} \mathrm{O}$. Reactions of the tri(alkynes) 2 with 3.3 equiv of 1-D2 and 1-D3 afforded the PAMAM dendrimers 4-G2 and 4-G3 in yields of 90 and $76 \%$, respectively, after 9 and $12 \mathrm{~h}$, which were separated by column chromatography. The low yields, in the absence of any side product(s) as observed by TLC, could be due to significant retention of the polar dendrimer in the silica column. For completion of the reaction between the dendritic azide and the alkynes, the higher generation dendron takes longer time than the lower generation dendron, which can be ascribed to the steric demand of the dendron and spatial congestion of core region.

The symmetric PAMAM dendrimers were purified by column chromatography and the structures were confirmed by ${ }^{1} \mathrm{H}$ and ${ }^{13} \mathrm{C}$ NMR spectroscopy, IR spectroscopy, and FAB or MALDI mass spectra. From the ${ }^{1} \mathrm{H}$ NMR spectra $\left(\mathrm{CDCl}_{3}\right)$, the peaks of the methylene protons adjacent to the nitrogen of triazole, the triazole proton, and the methylene 


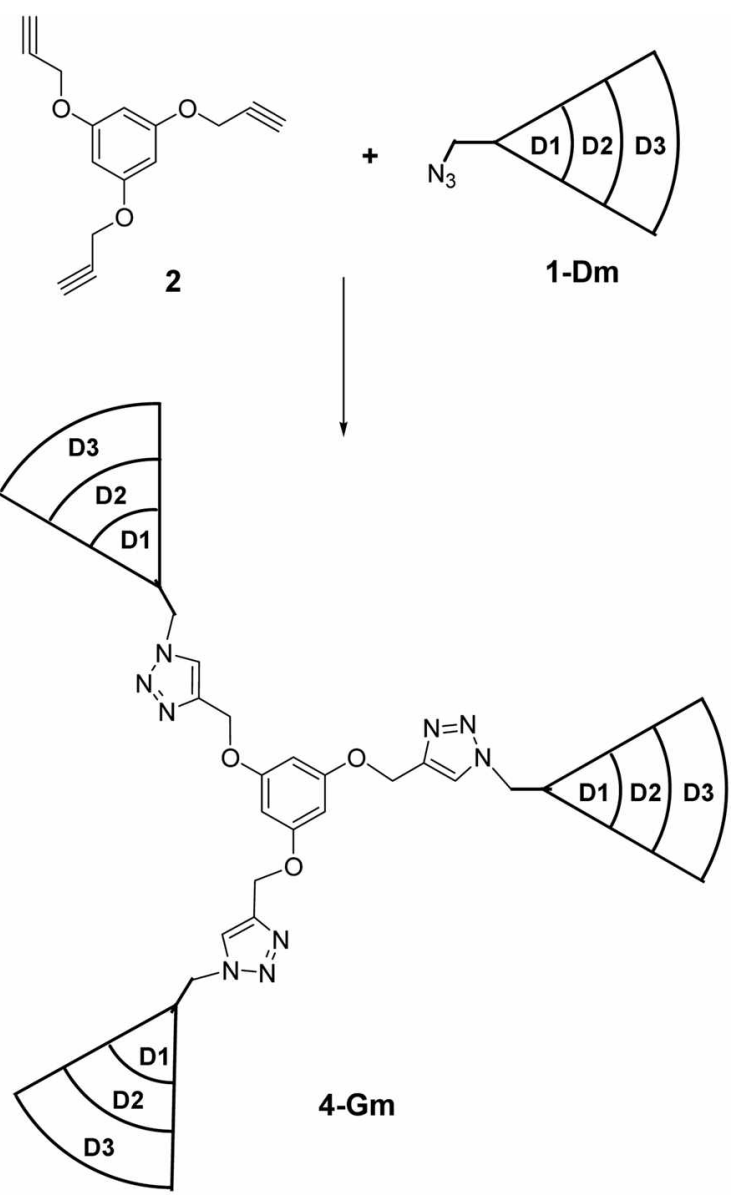

Scheme 2. Reagents and conditions: $15 \mathrm{~mol} \%$ of CuSO $\mathrm{CH}_{4} 5 \mathrm{H}_{2} \mathrm{O} / 30$ mol $\%$ of sodium ascorbate, $\mathrm{THF} / \mathrm{H}_{2} \mathrm{O}(4: 1)$, r.t.

protons adjacent to the carbon of triazole in dendrimers 4Gm were found at 4.37, 7.77, and 5.13 ppm for 4-G1, 4.36, 7.81 , and $5.07 \mathrm{ppm}$ for 4-G2, and 4.40,7.88, and $5.09 \mathrm{ppm}$ for 4-G3, respectively (Figure 3 ). The peaks of the amide protons $(\mathrm{NH})$ in the ${ }^{1} \mathrm{H}$ NMR spectra were found at 6.98 ppm for 4-G2, and at 7.01 and 7.54 ppm for 4-G3, respectively. As the dendrimer generation increased, the peaks of the triazole proton shifted gradually to down-field which may be influenced by the dendritic microenvironment effect. $^{12}$ IR data also confinmed that neither alkyne $(\sim 3290$ $\left.\mathrm{cm}^{-1}\right)$ nor azide $\left(-2098 \mathrm{~cm}^{-1}\right)$ residues remain in the final dendrimer (Figure 4). Their FAB or MALDI mass spectra exhibited very good correlation with the calculated molecular masses. Analysis of the dendrimers by ge]-permeation chromatography (GPC) from THF eluent shows very low polydispersity values $\mathrm{PDI}=1.02$ and 1.03 for 4-G1 and 4G2, respectively (Figure 5). Unfortunately, PDI value by GPC analysis of 4-G3 could not be obtained due to their poor solubility and aggregation property in THF.

To probe the viability of our approach, we next tumed our attention toward the construction of PAMAM dendrimers 5Gm with tetra(alkynes) 3 (Scheme 3 ). The reaction of the tetra(alkynes) 3 and 4.4 equiv of azide-dendrons 1-D1 in the presence of $0.1,0.2,0.5$, and 1.0 equiv of $\mathrm{CuI}$ with respect to the alkyne in THF $(0.1 \mathrm{M})$ did not occur at room temper-

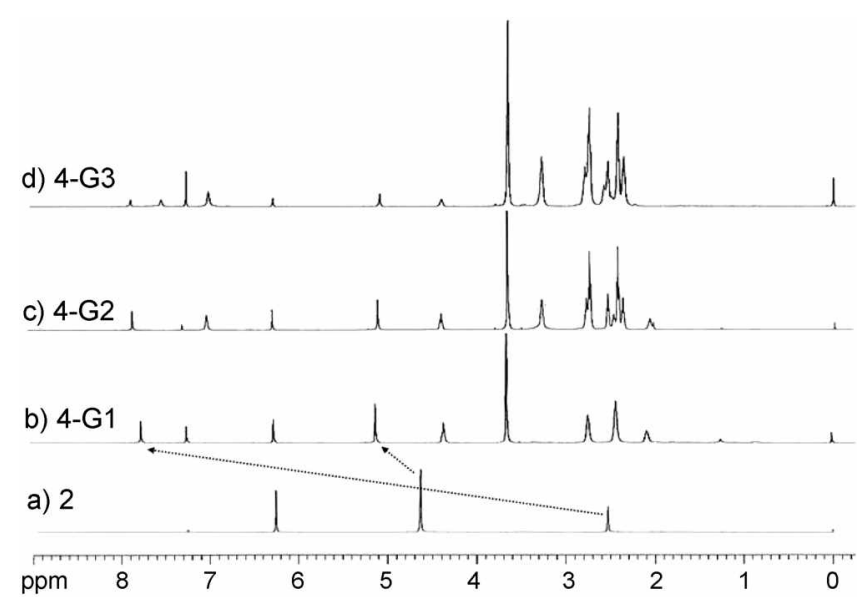

Figure 3. 'H-NMR spectra for (a) 2, (b) 4-G1, (c) 4-G2, and (d) 4G3.

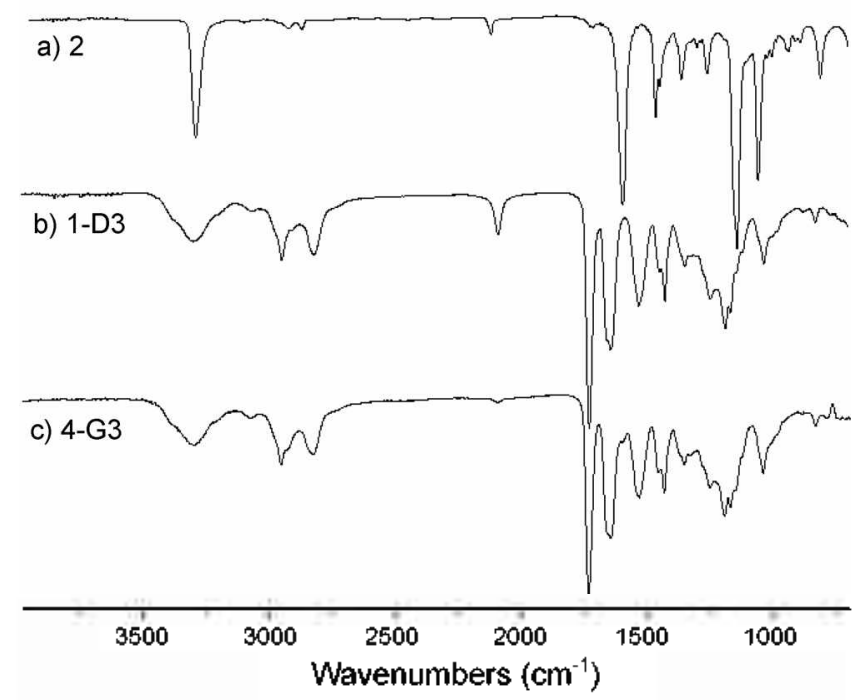

Figure 4. IR spectra for (a) 2, (b) 1-D3, and (c) 4-G3.

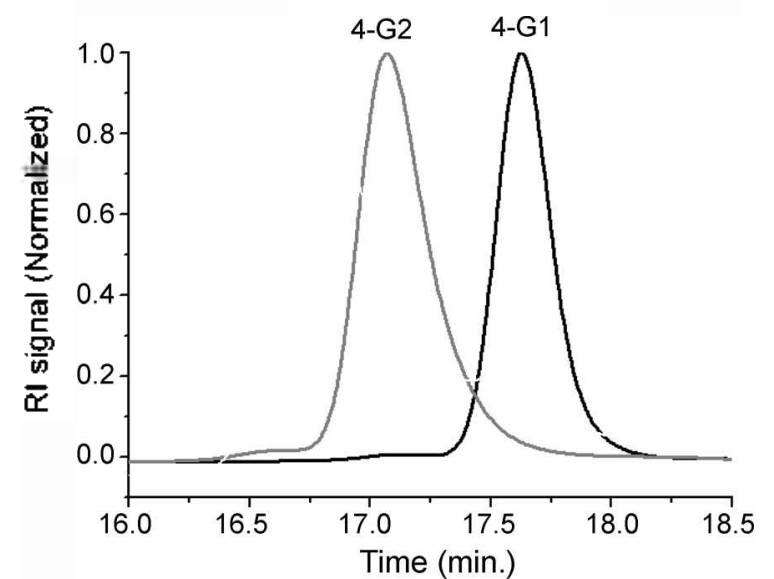

Figure 5. GPC diagrams of dendrimers 4-G1 and 4-G2 obtained from THF eluent.

ature. However, the reaction proceeded at $50^{\circ} \mathrm{C}$ smoothly to afford the desired product 5-G1 irrespective of the amount of $\mathrm{CuI}$ used. We have found that the reaction conducted in 5 mol $\%$ of $\mathrm{CuSO}_{4} \cdot 5 \mathrm{H}_{2} \mathrm{O}$ and $10 \mathrm{~mol} \%$ of sodium ascorbate 

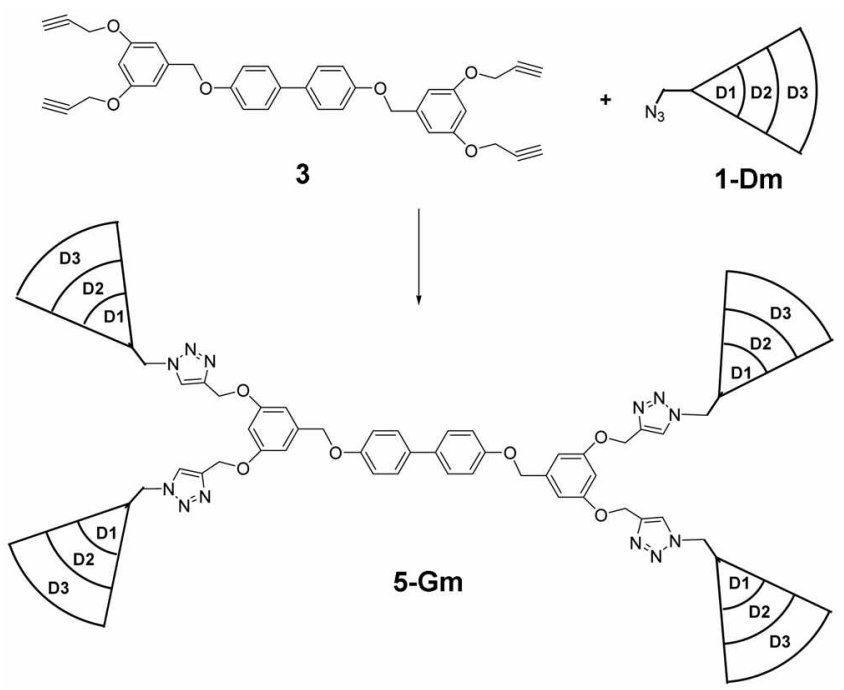

Scheme 3. Reagents and conditions: $20 \mathrm{~mol} \%$ of $\mathrm{CuSO}_{4} \cdot 5 \mathrm{H}_{2} \mathrm{O} / 40$ mol $\%$ of sodium ascorbatc, DMF/ $/ \mathrm{H}_{2} \mathrm{O}(4 ; 1), 60^{\circ} \mathrm{C}$.

with respect to the alkyne in a $4: 1$ solvent ratio of DMF to $\mathrm{H}_{2} \mathrm{O}$ proceeded smoothly at room temperature and finished within $9 \mathrm{~h}$ at $60^{\circ} \mathrm{C}$ providing the desired product 5-G1 in an isolated yield of $97 \%$. The generation and disappearance of the mono, di, and tri-triazole derivatives were monitored by TLC runs of the reaction mixture. Based on these optimizations for the synthesis of the first generation dendrimer, we fixed conditions for higher generation dendrimers. Therefore we tried to synthesize higher generation dendrimers with $5 \mathrm{~mol} \%$ of $\mathrm{CuSO}_{4} \cdot 5 \mathrm{H}_{2} \mathrm{O}$ and $10 \mathrm{~mol} \%$ of sodium ascorbate with respect to the alkyne in a $4: 1$ solvent ratio of DMF to $\mathrm{H}_{2} \mathrm{O}$ (Scheme 3). The reactions of the tetra(alkynes) 3 and 4.4 equiv of alkyne-dendrons 1-D2 and 1-D3 afforded the PAMAM dendrimers $\mathbf{5 - G 2}$ and $\mathbf{5 - G 3}$ in yields of $91 \%$ and $86 \%$, respectively, after 12 and $18 \mathrm{~h}$, which were separated by column chromatography. The low yields, in the absence of any side product(s) as observed by TLC, could be due to significant retention of the polar dendrimer in the silica column. For completion of the reaction between the dendritic azide and the alkyne, the higher generation dendron takes longer time than the lower generation dendron, which can be differentiated by the accessibility of azide group due to the steric hindrance (bulkiness) of dendron and spatial congestion of core region. This observation led us to imagine that the reaction between the dendritic azide and the alkyne was kinetically controlled. This result showed that the formation of triazole could be regarded as a new connector to construct the symmetric PAMAM dendrimers from dendrons. Self-emissive dendrimer showed the characteristic potential applications such as diagnostic and imaging. With this in mind we are now investigated for self-emissive PAMAM dendrimer with a fluorescent or phosphorescent probe in core region. The triazole residues existing in dendrimers can stabilize $\mathrm{Cu}(\mathrm{I})$ species even under aqueous aerobic conditions which may play a crucial role in biological applications. Their copper-binding ability may be used as the ligand properties in homogeneous catalysis.
The structures of the PAMAM dendrimers were also confinmed by ${ }^{1} \mathrm{H}$ and ${ }^{13} \mathrm{C}$ NMR spectroscopy, IR spectroscopy, FAB and MALDI mass spectra. From the 'H NMR spectra $\left(\mathrm{CDCl}_{3}\right)$, the peaks of the methylene protons adjacent to the nitrogen of triazole, the triazole proton, and the methylene protons adjacent to the carbon of triazole in dendrimers 5-Gm were found at 4.36,7.76, and $5.19 \mathrm{ppm}$ for 5-G1, 4.39, 7.84, and 5.16 ppm for 5-G2, and 4.41, 7.90, and $5.19 \mathrm{ppm}$ for $5-\mathbf{G 3}$, respectively. The peaks of the amide protons $(\mathrm{NH})$ in the ' $\mathrm{H}$ NMR spectra were found at 6.95 ppm for 5-G2, and at 7.00 and 7.44 ppm for 5-G3, respectively. As the dendrimer generation increased, the peaks of the methylene protons adjacent to the nitrogen of triazole and the triazole proton shifted gradually to down-field which may be influenced by the dendritic microenvironment effect. ${ }^{12}$ The IR spectra shows the disappearance of the acetylene peak at $\sim 3290 \mathrm{~cm}^{-1}$ and the azide peak at $\sim 2096$ $\mathrm{cm}^{-1}$ in the final dendrimer while the 'H NMR revealed no alkyne peak at around $\delta 2.53 \mathrm{ppm}$. Their FAB or MALDI mass spectra were exhibited very good correlation with the calculated molecular masses. Analysis of the dendrimers by gel-pemeation chromatography (GPC) from THF eluent shows very low polydispersity value PDI $=1.02$ for $5-\mathbf{G 1}$ which means no signs of products with defects that would arise from incomplete coupling. Unfortunately, PDI values by GPC analysis of 5-G2 and 5-G3 could not be obtained due to their poor solubility and aggregation property in THF.

In summary, we have demonstrated that click reactions between the tri(alkynes) core or tetra(alkynes) core and the azide-functionalized PAMAM dendrons lead to the formation of symmetric PAMAM-like dendrimers in high yields. This method can be applied for the fast synthesis of PAMAM-like dendrimers with different lengths (spacers) and/or functional goups at core and may then provide an insight into designing various dendrimers with the functional cores. We are currently working toward synthesis of various functional dendrimers using this strategy for various applications.

\section{Experimental Section}

'H NMR spectra were recorded on a 300 or $500 \mathrm{MHz}$ NMR spectrometer using the residual proton resonance of the solvent as the internal standard. Chemical shifts are reported in parts per million (ppm). When peak multiplicities are given, the following abbreviations are used: $s$, singlet; $d$, doublet; $t$, triplet; $q$, quartet; quin, quintet; $d$ of $d$, doublet of a doublet; $m$, multiplet; br, broad. ${ }^{13} \mathrm{C}$ NMR spectra were proton decoupled and recorded on a 75 or 125 $\mathrm{MHz}$ NMR spectrometer using the carbon signal of the deuterated solvent as the internal standard. FAB and MALDI mass spectra were obtained from Korea Basic Science Institute (KBSI) in Daegu or Daejeon and POSTECH. Flash chromatography was performed with $37-75 \mu \mathrm{m}$ silica gel. Analytical thin layer chromatography was performed on silica plates with $\mathrm{F}_{254}$ indicator and the visualization was accomplished by UV lamp or using an jodine chamber. 
Polydispersity (PDI) of dendrimers was determined by gel permeation chromatography (GPC) analysis relative to polystyrene calibration (Agilent 1100 series GPC, Plgel 5 $\mu \mathrm{m}$ MIXED-C, refractive index detector) in THF solution. All chemicals were obtained from commercial sources and used as received, unless otherwise mentioned. THF was distilled over $\mathrm{Na} / \mathrm{Ph}_{2} \mathrm{CO}$ ketyl.

Synthesis of 1,3,5-tris(prop-2-ynyloxy)benzene (2). A solution of benzene-1,3,5-triol $(0.5 \mathrm{~g}, 3.09 \mathrm{mmol})$ and propargyl bromide $(1.3 \mathrm{~g}, 10.80 \mathrm{mmol})$ and 18 -crown- $6(0.06 \mathrm{~g}$, $0.62 \mathrm{mmol})$ in $\mathrm{CH}_{3} \mathrm{CN}(30 \mathrm{~mL})$ in the presence of $\mathrm{K}_{2} \mathrm{CO}_{3}$ $(1.5 \mathrm{~g}, 10.80 \mathrm{mmol})$ was stirred under reflux for $16 \mathrm{~h}$. The reaction mixture was added to EtOAc $(50 \mathrm{~mL})$ and the resulting solution was washed with brine $(20 \mathrm{~mL} \times 3)$. The organic phase was dried with magnesium sulfate and concentrated. The residue was purified by recrystallization (EtOAc/n-hexane system) and column chromatography (EtOAc/n-hexane, $1: 6$ ) to afford the desired product $2(0.49$ g, 66\%). Mp. $65-68^{\circ} \mathrm{C}$. IR $3289,2122,1602,1472,1266$, $1368,1146,1066,1038,1014 \mathrm{~cm}^{-1} ;{ }^{1} \mathrm{H}$ NMR $(500 \mathrm{MHz}$, $\left.\mathrm{CDCl}_{3}\right): \delta=2.53(\mathrm{~m}, 3 \mathrm{H}), 4.64(\mathrm{~m}, 6 \mathrm{H}), 6.27(\mathrm{~m}, 3 \mathrm{H}) ;{ }^{13} \mathrm{C}$ $\operatorname{NMR}\left(125 \mathrm{MHz}, \mathrm{CDCl}_{3}\right): \delta=159.8,95.9,78.7,76.2,56.4$.

Synthesis of 4,4'-(3,5-bis(propargyloxy)benzyloxy)bisphenyl (3). A solution of 3,5-bis(propargyloxy)benzyl chloride $(110 \mathrm{mg}, 0.47 \mathrm{mmol})$ and $4,4^{\prime}$-bisphenol $(40 \mathrm{mg}$, $0.21 \mathrm{~mol})$ in DMF $(2 \mathrm{~mL})$ in the presence of $\mathrm{K}_{2} \mathrm{CO}_{3}(58.9$ $\mathrm{mg}, 0.43 \mathrm{mmol}$ ) was stirred at $60^{\circ} \mathrm{C}$ for $24 \mathrm{~h}$. The reaction mixture was added to EtOAc $(50 \mathrm{~mL})$ and the resulting solution was washed with brine $(20 \mathrm{~mL} \times 3)$. The organic phase was dried with magnesium sulfate and concentrated. The residue was purified by column chromatography (EtOAc/n-hexane, $1: 4$ ) to afford the desired product 2 (122 mg, $98 \%$ ). Mp. $98-100^{\circ} \mathrm{C}$. IR 3290, 2921, 2854, 2121, 1590 , $1494,1452,1292,1269,1241,1148,1055,1038,1014 \mathrm{~cm}^{-1}$; 'H NMR (500 MHz, CDCl $): \delta=2.52(\mathrm{~m}, 4 \mathrm{H}), 4.69(\mathrm{~d}, J=$ $2.3 \mathrm{~Hz}, 8 \mathrm{H}), 5.06(\mathrm{~s}, 4 \mathrm{H}), 6.58(\mathrm{~m}, 2 \mathrm{H}), 6.72(\mathrm{~m}, 4 \mathrm{H}), 7.01$ $(\mathrm{d}, J=8.6 \mathrm{~Hz}, 4 \mathrm{H}), 7.46(\mathrm{~d}, J=8.6 \mathrm{~Hz}, 4 \mathrm{H}) ;{ }^{13} \mathrm{C} \mathrm{NMR}(125$ $\mathrm{MHz}, \mathrm{CDCl}_{3}$ ): $\delta=159.3,158.2,140.1,134.2,128.2,115.6$, $107.2,102.2,78.7,76.2,70.2,56.4$; MS (FAB): $m / z=582$ [M+ ${ }^{+}$; HRMS (FAB) caled for $\mathrm{C}_{38} \mathrm{H}_{30} \mathrm{O}_{6}: 582.2042$. found: $583.2121\left[\mathrm{M}^{+}+\mathrm{H}\right]$.

General procedure for the preparation of PAMAM dendrimers 4-Gm from azide-PAMAM dendrons 1-Dm and tri(alkyne) core 2 . A mixture of azido-dendrons 1-Dm $(0.21 \mathrm{mmol})$ and $1,3,5$-tris-prop-2-ynyloxybenzene $2(0.05$ $\mathrm{mmol})$ in $\mathrm{THF}-\mathrm{H}_{2} \mathrm{O}(4: 1,1 \mathrm{~mL})$ in the presence of $15 \mathrm{~mol}$ $\% \mathrm{CuSO}_{4} \cdot 5 \mathrm{H}_{2} \mathrm{O}$ with 30 mol $\%$ sodium ascorbate was stirred at room temperature for $\sim 13 \mathrm{~h}$. The reaction mixture was poured into brine $(20 \mathrm{~mL})$ and the resulting solution was extracted with EtoAc $(20 \mathrm{~mL} \times 3)$. The combined organic phase was dried with sodium sulfate, concentrated, and purified by column chromatography (EtOAc/methanol system) to afford the desired product.

4-G1: $90 \%$ yield; IR 3142, 2952, 2832, 1734, 1597, 1461, $1437,1256,1200,1162,1048 \mathrm{~cm}^{-1} ;{ }^{1} \mathrm{H}$ NMR $(500 \mathrm{MHz}$, $\left.\mathrm{CDCl}_{3}\right): \delta=2.07(\mathrm{~m}, 6 \mathrm{H}), 2.42(\mathrm{~m}, 18 \mathrm{H}), 2.73(\mathrm{~m}, 12 \mathrm{H})$, $3.66(\mathrm{~s}, 18 \mathrm{H}), 4.37(\mathrm{t}, J=6.9 \mathrm{~Hz}, 6 \mathrm{H}), 5.13(\mathrm{~s}, 6 \mathrm{H}), 6.29(\mathrm{~s}$,
$3 \mathrm{H}), 7.77(\mathrm{~s}, 3 \mathrm{H}) ;{ }^{13} \mathrm{C} \mathrm{NMR}\left(75 \mathrm{MHz}, \mathrm{CDCl}_{3}\right): \delta=173.3$, $160.5,143.9,123.8,95.2,62.4,52.0,50.7,49.5,48.3,32.7$, 28.4; MS (FAB): $m / z=1058$ [M $\left.\mathrm{M}^{+}+\mathrm{H}\right]$; HRMS (FAB) caled for $\mathrm{C}_{48} \mathrm{H}_{72} \mathrm{~N}_{12} \mathrm{O}_{15}: 1056.5240$. found: $1057.5318\left[\mathrm{M}^{+}+\mathrm{H}\right]$. $\mathrm{PDI}=1.02$.

4-G2: $90 \%$ yield; IR 3313, 2952, 2827, 1735, 1664, 1601, $1534,1461,1436,1256,1198,1171,1046 \mathrm{~cm}^{-1}$; 'H NMR $\left(500 \mathrm{MHz}, \mathrm{CDCl}_{3}\right): \delta=2.01(\mathrm{t}, J=6.2 \mathrm{~Hz}, 6 \mathrm{H}), 2.32(\mathrm{t}, J=$ $6.2 \mathrm{~Hz}, 12 \mathrm{H}), 2.37$ (t, $J=6.5 \mathrm{~Hz}, 24 \mathrm{H}), 2.42$ (t, $J=5.7 \mathrm{~Hz}$, $6 \mathrm{H}), 2.49(\mathrm{t}, J=5.7 \mathrm{~Hz}, 12 \mathrm{H}), 2.69(\mathrm{t}, J=6.6 \mathrm{~Hz}, 24 \mathrm{H}), 2.73$ $(\mathrm{t}, J=6.1 \mathrm{~Hz}, 12 \mathrm{H}), 3.21-3.24(\mathrm{~m}, 12 \mathrm{H}), 3.61(\mathrm{~s}, 36 \mathrm{H}), 4.36$ $(\mathrm{t}, J=6.8 \mathrm{~Hz}, 6 \mathrm{H}), 5.07(\mathrm{~s}, 6 \mathrm{H}), 6.24(\mathrm{~s}, 3 \mathrm{H}), 6.98(\mathrm{t}, J=4.9$ $\mathrm{Hz}, 6 \mathrm{H}), 7.81(\mathrm{~s}, 3 \mathrm{H}) ;{ }^{13} \mathrm{C}$ NMR $\left(75 \mathrm{MHz}, \mathrm{CDCl}_{3}\right): \delta=$ $173.4,172.7,160.6,144.0,123.7,95.3,62.3,53.3,52.0$, $50.3,50.0,49.6,48.4,37.6,34.3,33.0,28.5$; MS (MALDI): $m / z$ calcd for $\mathrm{C}_{102} \mathrm{H}_{1688} \mathrm{~N}_{24} \mathrm{O}_{33}: 2257.2206$. found: 2258.2581 $\left[\mathrm{M}^{+}+\mathrm{H}\right], 2280.2764\left[\mathrm{M}^{+}+\mathrm{Na}\right] . \mathrm{PDI}=1.03$.

4-G3: $76 \%$ yield; $\mathbb{R}$ 3293, 2952, 2827, 1735, 1658, 1537, $1461,1436,1257,1198,1176,1045 \mathrm{~cm}^{-1}$; ${ }^{1} \mathrm{H}$ NMR $(500$ $\left.\mathrm{MHz}, \mathrm{CDCl}_{3}\right): \delta=2.03(\mathrm{~m}, 6 \mathrm{H}), 2.34(\mathrm{~m}, 36 \mathrm{H}), 2.41(\mathrm{t}, J=$ $6.1 \mathrm{~Hz}, 48 \mathrm{H}), 2.52-2.53(\mathrm{~m}, 30 \mathrm{H}), 2.57(\mathrm{~m}, 12 \mathrm{H}), 2.73(\mathrm{t}, J=$ $6.3 \mathrm{~Hz}, 60 \mathrm{H}), 2.78(\mathrm{~m}, 24 \mathrm{H}), 3.26-3.27(\mathrm{~m}, 36 \mathrm{H}), 3.64(\mathrm{~s}$, $72 \mathrm{H}), 4.40(\mathrm{t}, J=6.2 \mathrm{~Hz}, 6 \mathrm{H}), 5.09(\mathrm{~s}, 6 \mathrm{H}), 6.28(\mathrm{~s}, 3 \mathrm{H})$, 7.01 (br s, $12 \mathrm{H}), 7.54$ (br s, 6H), 7.88 (s, 3H) ${ }^{13} \mathrm{C} \mathrm{NMR}(125$ $\left.\mathrm{MHz}_{2} \mathrm{CDCl}_{3}\right): \delta=173.4,173.0,172.7,160.7,143.9,123.8$, $95.1,62.3,53.3,52.9,52.0,50.2,50.1,49.6,48.6,37.9,37.6$, $34.4,34.2,33.1,28.6$; MS (MALDI): $\mathrm{m} / \mathrm{z}$ caled for $\mathrm{C}_{210} \mathrm{H}_{360} \mathrm{~N}_{48} \mathrm{O}_{69}: 4658.6137$. found: $4681.7505\left[\mathrm{M}^{+}+\mathrm{Na}\right]$.

General procedure for the preparation of symmetric PAMAM dendrimers 5-Gm from azide-PAMAM dendrons 1-Dm and tetra(alkyne) core 4. A mixture of azidodendrons 1-Dm $(0.21 \mathrm{mmol}$ ) and 4,4-(3,5-bis(propargyloxy)benzyloxy)bisphenyl $4(0.05 \mathrm{mmol})$ in THF- $\mathrm{H}_{2} \mathrm{O}(4: 1$, $1 \mathrm{~mL}$ ) in the presence of $20 \mathrm{~mol} \% \mathrm{CuSO}_{4} \cdot 5 \mathrm{H}_{2} \mathrm{O}$ with 40 mol $\%$ sodium ascorbate was stirred at $60^{\circ} \mathrm{C}$ for $\sim 18 \mathrm{~h}$. The reaction mixture was poured into brine $(20 \mathrm{~mL})$ and the resulting solution was extracted with EtoAc $(20 \mathrm{~mL} \times 3)$. The combined organic phase was dried with sodium sulfate, concentrated, and purified by column chromatography (EtOAc/methanol system) to afford the desired product.

5-G1: $97 \%$ yield; IR 2952, 2849, 1732, 1655, 1595, 1436, $1214,1172,1044 \mathrm{~cm}^{-1} ;{ }^{1} \mathrm{H}$ NMR $\left(500 \mathrm{MHz}, \mathrm{CDCl}_{3}\right): \delta=$ $2.07(\mathrm{~m}, 8 \mathrm{H}), 2.42(\mathrm{~m}, 24 \mathrm{H}), 2.72(\mathrm{~m}, 16 \mathrm{H}), 3.66(\mathrm{~s}, 24 \mathrm{H})$, $4.36(\mathrm{t}, J=6.3 \mathrm{~Hz}, 8 \mathrm{H}), 5.03(\mathrm{~s}, 4 \mathrm{H}), 5.19(\mathrm{~s}, 8 \mathrm{H}), 6.61(\mathrm{~m}$, $2 \mathrm{H}), 6.72(\mathrm{~m}, 4 \mathrm{H}), 6.99(\mathrm{~d}, J=8.3 \mathrm{~Hz}, 4 \mathrm{H}), 7.45(\mathrm{~d}, J=8.1$ $\mathrm{Hz}, 4 \mathrm{H}), 7.76(\mathrm{~s}, 4 \mathrm{H}) ;{ }^{13} \mathrm{C} \mathrm{NMR}\left(125 \mathrm{MHz}, \mathrm{CDCl}_{3}\right): \delta=$ $173.4,160.1,144.0,128.2,123.7,115.5,106.9,62.6,52.0$, $50.8,49.5,48.4,32.8,28.5$; MS (FAB): $m / z=1671.1\left[\mathrm{M}^{+}+\right.$ H], $1693.1\left[\mathrm{M}^{+}+\mathrm{Na}\right]$; HRMS (FAB) caled for $\mathrm{C}_{82} \mathrm{H}_{110} \mathrm{~N}_{16} \mathrm{O}_{22}$ : 1670.7981. found: $1671.8059\left[\mathrm{M}^{+}+\mathrm{H}\right] . \mathrm{PDI}=1.02$.

5-G2: $91 \%$ yield; IR 3278, 2955, 2923, 2852, 1732, 1652, $1595,1576,1436,1217,1172,1044 \mathrm{~cm}^{-1}$; 'H NMR $(500$ $\left.\mathrm{MHz}, \mathrm{CDCl}_{3}\right): \delta=2.03(\mathrm{~m}, 8 \mathrm{H}), 2.34(\mathrm{~m}, 16 \mathrm{H}), 2.40(\mathrm{~m}$, $40 \mathrm{H}), 2.52(\mathrm{~m}, 16 \mathrm{H}), 2.72(\mathrm{~m}, 48 \mathrm{H}), 3.26(\mathrm{~m}, 16 \mathrm{H}), 3.64(\mathrm{~s}$, $48 \mathrm{H}), 4.39(\mathrm{~m}, 8 \mathrm{H}), 5.02(\mathrm{~s}, 4 \mathrm{H}), 5.16(\mathrm{~s}, 8 \mathrm{H}), 6.61(\mathrm{~m}, 2 \mathrm{H})$, $6.72(\mathrm{~m}, 4 \mathrm{H}), 6.95(\mathrm{br} \mathrm{s}, 8 \mathrm{H}), 6.99(\mathrm{~d}, J=6.7 \mathrm{~Hz}, 4 \mathrm{H}), 7.46$ $(\mathrm{d}, J=6.7 \mathrm{~Hz}, 4 \mathrm{H}), 7.84(\mathrm{~s}, 4 \mathrm{H}) ;{ }^{13} \mathrm{C} \mathrm{NMR}\left(75 \mathrm{MHz}, \mathrm{CDCl}_{3}\right)$ : 
$\delta=173.4,172.8,160.1,144.1,128.1,123.7,115.5,106.8$, $62.4,53.3,52.0,50.3,50.0,49.6,48.4,37.6,34.4,33.1,28.6$; MS (MALDI): $m / z$ calcd for $\mathrm{C}_{1,34} \mathrm{H}_{238} \mathrm{~N}_{32} \mathrm{O}_{46}: 3271.7268$. found: $3272.7329\left[\mathrm{M}^{+}+\mathrm{H}\right]$.

5-G3: $86 \%$ yield; IR $3270,2951,2832,1734,1650,1550$, $1436,1217,1175,1044 \mathrm{~cm}^{-1}$; 'H NMR ( $\left.500 \mathrm{MHz}, \mathrm{CDCl}_{3}\right)$ : $\delta=2.03(\mathrm{~m}, 8 \mathrm{H}), 2.35(\mathrm{~m}, 36 \mathrm{H}), 2.42(\mathrm{~m}, 84 \mathrm{H}), 2.53(\mathrm{~m}$, $48 \mathrm{H}), 2.73-2.75(\mathrm{~m}, 112 \mathrm{H}), 3.27-3.33(\mathrm{~m}, 48 \mathrm{H}), 3.69(\mathrm{~s}$, $96 \mathrm{H}), 4.41(\mathrm{~m}, 8 \mathrm{H}), 5.06(\mathrm{~s}, 4 \mathrm{H}), 5.19(\mathrm{~s}, 8 \mathrm{H}), 6.56(\mathrm{~m}, 2 \mathrm{H})$, $6.67(\mathrm{~m}, 4 \mathrm{H}), 7.00$ (br, $16 \mathrm{H}), 7.10$ (br, $4 \mathrm{H}), 7.37$ (br, $4 \mathrm{H})$, $7.44(\mathrm{br}, 8 \mathrm{H}), 7.90(\mathrm{~s}, 4 \mathrm{H}) ;{ }^{13} \mathrm{C}$ NMR $\left(125 \mathrm{MHz}, \mathrm{CDCl}_{3}\right): \delta$ $=173.52,173.5,172.8,160.1,144.1,128.1,115.5,106.9$, $62.3,53.2,52.2,52.0,50.4,50.2,49.8,49.6,48.8,37.6,34.4$, $33.1,32.7,32.6,32.5,28.6$; MS (MALDI): $m / z$ calcd for $\mathrm{C}_{298} \mathrm{H}_{494} \mathrm{~N}_{64} \mathrm{O}_{94}: 6473.5843$.

Acknowledgement. This research was supported by the University IT Research Center (ITRC) Project of the Ministry of Information and Communication (J.W.L) and the National Research Laboratory (NRL) program of KOSEF (S.H.J). We also thank the Korean Ministry of Education (BK 21 Program) for graduate studentships.

\section{References}

1. (a) Grimsdale, A. C.; Müllen, K. Angew, Chem. Int. Ed. 2005, 44, 5592. (b) Tomalia, D. A. Prog. Polym. Sci. 2005, 30, 294.

2. (a) Hawker, C. J.; Fréchet, J. M. J. J. Am. Chem. Soc. 1990, I/2, 7638. (b) Hawker, C. J.; Fréchet, J. M. J. J. Chen. Soc, Chent. Contnitf. 1990, 1010. (c) Grayson, S. M.; Fréchet. J. M. J. Chent. Rev: 2001, 101, 3819 .

3. (a) Tomalia, D. A.; Baker, H.; Dewald, J.; Hall, M.; Kallos, G. Martin, S.; Roeck, J.; Ryder, J.; Smith, P. Polym. J. 1985, 17, 117. (b) Tomalia, D. A.; Naylor, A. M.; Goddard III, W. A. Angew: Chem., Int. Ed. Engl. 1990, 29, 138.

4. (a) Majoros, I. J.; Myc, A.; Thomas, T.; Mehta, C. B.; Baker, J. R. Jt. Biomacromolecules 2006, 7, 572, (b) Gupta, U.; Agashe, H. B.; Asthana, A.; Jain, N. K. Biomacromolectles 2006, 7, 649. (c) Ambade, A. V.; Savariar, E. N.; Thayumanavan, S. Mol. Pharm. 2005, 2, 264. (d) Venditto, V. J.; Reoino, C. A. S.; Brechbiel. M. W. Mol. Pharm. 2005, 2, 302. (e) McCarthy, T. D.; Karellas, P.; Henderson, S. A.; Giannis, M.; O'Keefe, D. F.; Heery, G.; Paull, J. R. A.; Mathews, B. R.; Holan, G Mol. Phorm. 2005, 2, 312 .
5. Pittelkow, M.; Christensen, J. B. Org, Lett. 2005, 7, 1295.

6. (a) Newkome, G. R.; Moorefield, C. N.; Vögtle, F. Dendrimers and Dendrons: Concepts, Synthesis, Apptications; Wiley-VCH: Weinheim, 200I. (b) Fréchet. J. M. J.; Tomalia, D. A. Dendrimers and Other Dendritic Polyners; John Wiely \& Sons Lid. 2001 .

7. Kolb, H. C.; Finn, M. G; Sharpless, K. B. Angen: Chent. Int. Ed. $2001,40,2004$

8. (a) Rostovtsev, V. V.; Green, L. G.; Fokin. V. V.; Sharpless, K. B. Angew, Chem. Int. Ed. 2002, 4l, 2596. (b) Tomae, C. W; Christensen, C.; Meldal, M. J. Org. Chem. 2002, 67, 3057.

9. Bock, V. D.; Hiemstra, H.; van Maarseveen, J. H. Ezr: J. Org. Chent 2006, 51.

10. (a) Wu, P.; Feldman, A. K.; Nugent, A. K.; Hawker, C. J.; Scheel, A.; Voit, B.; Pyun. J.; Fréchet, J. M. J.; Sharpless, K. B.; Fokin, V. V. Angew. Chem. Int, Ed. 2004, 43, 3928. (b) Helms, B.; Mynar, J. L.; Hawker, C. J.; Fréchet, J. M. J. J. Ant. Chem. Soc. 2004, 126, 15020. (c) Malkoch, M.; Schleicher, K.; Drockenmuller, E.; Hawker, C. J.; Russell, T. P.; Wu, P.; Fokin. V. V. Macrontolectles 2005, 38, 3663. (d) Joralemon, M. J.; O'Reilly, R. K.; Matson, J. B.; Nugent, A. K.; Hawker, C. J.; Wooley, K. L. Macronolecttes 2005, 38, 5436. (e) Lee, J. W, Kim, B, K. Bull. Korean Chem. Soc. 2005, 26, 658. (ก) Lee, J. W; Kim, B. K.; Jin, S. H. Bull. Korean Chem. Soc. 2005, 26, 833. (g) Lee, J. W, Kim, B. K,; Kim. J. H.; Shin, W. S.; Jin, S. H. Bull. Korean Chem. Soc. 2005 26, 1790. (h) Rijkers, D. T. S.; van Esse, G. W.; Merkx. R.; Brouwer, A. J.; Jacobs, H. J. F.; Pieters, R. J.; Liskamp, R. M. J. Chem, Commw. 2005, 4581. (i) Mynar, J. L.; Choi, T.-L.; Yoshida, M.; Kim, V.; Hawker, C. J.; Fréchet, J. M. J. Chem. Commin, 2005, 5169. (j) Wu, P,; Malkoch, M.; Hunt, J. N.; Vestberg, R.; Kaltgrad, E.; Finn, M. G.; Fokin, V. V.; Sharpless, K. B.; Hawker. C. J. Chen. Conmitm. 2005, 5775. (k) Joosten. J. A. F.; Tholen, N. T. H.; Maate, F. A. E.; Brouwer, A. J.; van Esse, G. W.; Rijkers, D. T. S.; Liskamp, R. M. J.; Pieters, R. J. Eur. J. Org. Chem, 2005, 3182 . (1) Lee, J. W.; Kim, B. K. Symthesis 2006, 615. (m) Lee, J. W.; Kim, J. H.; Kim, B. K.; Shin, W. S.; Jin, S. H. Tetrahedron 2006, 62, 894 .

I1. (a) Lee, J. W.; Kim, B. K.; Kim, H. J.; Han, S. C.; Shin, W. S.; Jin, S. H. Macromolectles 2006, 39, 2418 . (b) Lee, J. W.; Kim, J. H.; Kim, B. K. Tetrahedron Lett. 2006, 47, 2683. (c) Lee, J. W.; Kim, B. K.; Kim, J. H.; Shin, W. S.; Jin, \$. H. J. Org. Chem. 2006, 7l, 4988. (d) Lee, J. W; Kim, J. H.; Kim, B. K.; Kim, J. H.; Shin, W. S.; Jin, S. H. Tetrahedron 2006, 62,9193.

12. (a) Mong. T. K.-K.; Niu, A.; Chow, H.-F.; Wu, C.; Li, L.; Chen, R. Chem. Eur. J. 2001, 7, 686. (b) Wong, C.-H.; Chow, H.-F.; Hui, S.K.; Sze, K.-H. Org. Lett. 2006, 8, I8I1. (c) Sun, H.; Kaifer, A. E. Org. Lett, $2005,7,3845$. 